\title{
$X$-ray vision in the arctic tundra: exploring how redox biogeochemistry influences ecosystem processes
}

\author{
ELIZABETH HERNDON ${ }^{1,2}$ LAUREN KINSMAN-
} COSTEllo $^{3}$, AleX MichaUd $^{4}$, DAVID EMERSON $^{4}$, WILLIAM BOWDEN 5

${ }^{1}$ Environmental Sciences Division, Oak Ridge National Laboratory; Oak Ridge TN, USA 37831;

(herndonem@ornl.gov)

${ }^{2}$ Department of Earth and Planetary Sciences, The University of Tennessee, Knoxville; Knoxville TN, USA 37996

${ }^{3}$ Department of Biological Sciences, Kent State University; Kent OH, USA 44240

${ }^{4}$ Bigelow Laboratory for Ocean Sciences; East Boothbay ME, USA 04544

${ }^{5}$ Department of Biological Sciences, University of Vermont; Burlington VT, USA 05405

Synchrotron-source $\mathrm{x}$-ray techniques can yield novel insights into biogeochemical processes by providing element speciation in complex natural materials. Here, multi-element $\mathrm{x}$-ray absorption spectroscopy (XAS) at the phosphorus (P), calcium $(\mathrm{Ca})$, and iron $(\mathrm{Fe}) \mathrm{K}$-edges was used to investigate geochemical controls on $\mathrm{P}$ solubility in the arctic tundra. Phosphorus is a limiting nutrient to many ecosystems, particularly arctic streams, but the role of geochemical processes in regulating $\mathrm{P}$ bioavailability across the tundra is poorly constrained. Although $\mathrm{P}$ is often assumed to cycle rapidly between decomposing organic matter and organisms, phosphate adsorption to $\mathrm{Fe}$ (oxyhydr)oxides may at least temporarily limit $\mathrm{P}$ solubility. We explored the hypothesis that $\mathrm{Fe}$ oxide minerals serve as phosphate traps at redox interfaces in arctic tundra. We investigated the geochemistry of soils and sediments spanning a terrestrial-aquatic gradient from hilltops to shallow ponds near Toolik Lake on the North Slope, Alaska. Surface soils were collected from three vegetation classes (tussock tundra, hilltop heath, and wet sedge meadow) representing contrasting topographic positions and hydrologic regimes. Sediments and biological iron mats were collected from multiple shallow ponds. Soils and sediments enriched in Fe(III) (oxyhydr)oxides, namely wet sedge soils and pond sediments containing biological $\mathrm{Fe}$ mats, exhibited spectral features consistent with Fe-bound phosphate. In contrast, upland soils and pond sediments devoid of $\mathrm{Fe}$ mats contained $\mathrm{P}$ associated with organic molecules and/or carbonates Thus, Fe (oxyhydr)oxides that accumulate along redox interfaces sequester phosphate and potentially contribute to $\mathrm{P}$ limitation in arctic ecosystems. 